Revista Brasileira de Cartografia

ISSN 1808-0936 | https://doi.org/10.14393/revbrascartogr

Sociedade Brasileira de Cartografia, Geodésia, Fotogrametria e Sensoriamento Remoto

\title{
Inundação Costeira por Elevação do Nível do Mar em Imbé e Tramandaí - RS
}

\section{Coastal Flooding by Elevation of the Sea Level in Imbé and Tramandaí - RS}

Ana Fatima da Silva ${ }^{1}$, Elírio Ernestino Toldo Junior. ${ }^{2}$, Arnold van Rooijen ${ }^{3}$, Cláudia Franca de Abreu ${ }^{4}$, Jorge Luiz Rodrigues Filho ${ }^{5}$, Ronaldo dos Santos da Rocha ${ }^{6}$ e Robson dos Santos Aquino ${ }^{7}$

1 Universidade Federal do Rio Grande do Sul, Programa de Pós-graduação em Geociências, Porto Alegre, Brasil. E-mail: ana.oceano@gmail.com.

ORCID: https://orcid.org/0000-0002-4549-4265

2 Universidade Federal do Rio Grande do Sul, Centro de Estudos de Geologia Costeira e Oceânica, Porto Alegre, Brasil. E-mail: toldo@ufrgs.br.

ORCID: https://orcid.org/0000-0002-5609-4339

3 University of Western Australia, Oceans Graduate School \& UWA Oceans Institute, Western Australia, Australia. E-mail: arnold.vanrooijen@uwa.edu.au.

ORCID: https://orcid.org/0000-0002-5013-2592

4 Coastal Connections Community, Western Australia, Australia. E-mail: claudia@ coastalconnections.earth

ORCID: https://orcid.org/0000-0001-9287-7843

5 Universidade Estadual de Santa Catarina, Departamento de Engenharia de Pesca e Ciências Biológicas, Laguna, Brasil E-mail: jorlrf@gmail.com

ORCID: https://orcid.org/0000-0002-3681-9806

6 Universidade Federal do Rio Grande do Sul, Departamento de Geodésia, Porto Alegre, Brasil. E-mail: ronaldo.rocha@ufrgs.br. ORCID: https://orcid.org/0000-0003-3135-2730

7 Universidade Federal do Rio Grande do Sul, Departamento de Geodésia, Porto Alegre, Brasil. E-mail: robgeo@ig.com.br.

ORCID: https://orcid.org/0000-0002-3863-9411

Resumo: Uma das consequências da elevação do nível do mar é predispor a população e o ecossistema à inundação costeira. A vulnerabilidade pode causar distintos impactos dependendo da cota do terreno e da extensão da área ocupada. Imbé e Tramandaí localizados no litoral norte do RS são dois municípios que apresentam cotas baixas e áreas densamente ocupadas. Através de levantamentos topográficos do terreno foi conduzida uma modelagem digital para determinação das cotas de inundação. Foram considerados sete cenários de elevação do nível do mar, a partir de um conjunto de eventos marinhos extremos registrados na área de estudo, resultantes da soma das variáveis oscilação mareal e sub-mareal. Também, foram somadas as oscilações da onda por galgamento. Além das condições de mar atual foram incorporada nesta análise as projeções futuras da variação do nível do mar de acordo com o IPCC. A menor cota de subida do nível foi de 2,07 m e a maior de 4,33 m. Os mapas gerados possibilitaram a descrição da vulnerabilidade à subida do nível do mar, bem como reconhecer os locais com maior inundação. A análise dos resultados permitiu observar que a extensão das áreas vulneráveis tende a aumentar e que os planos de gestão costeira dos municípios devem abordar a questão de inundação para que se possa mitigar as consequências deste processo.

Palavras-chave: Inundação costeira. Modelo digital de elevação. Elevação do nível do mar. Gestão costeira.

\begin{abstract}
One of the consequences of sea level rise is the predisposition of the population and the ecosystem to coastal flooding. The vulnerability can cause distinct impacts depending on the elevation of the terrain and the extent of the occupied area. Imbé and Tramandaí located on the northern coast of RS are two municipalities that present low elevation and densely occuppied area. A bathtub model was created from topographic data to determine flood levels. Seven sea level rise scenarios were considered, based on a set of extreme marine events recorded in the study area, resulting from the sum of the following variables: tidal and sub-tidal oscillation, and wave run-up. In addition to the current sea conditions, future projections of sea level variation were incorporated in this analysis according to the IPCC. The lowest level of elevation of the level was $2.07 \mathrm{~m}$ and the highest of $4.33 \mathrm{~m}$. The maps generated made it possible to describe the vulnerability to sea level rise, as well as to recognize the sites with the largest flood levels. The analysis of the results showed that the extent of vulnerable areas will increase with time and that the coastal management plans of the municipalities should address this in order to mitigate the consequences of possible flooding. Keywords: Coastal flood. Digital elevation model. Sea level rise. Coastal management.
\end{abstract}




\section{INTRODUÇÃO}

Cerca de 600 milhões de pessoas vivem na zona costeira com elevação abaixo de 10 metros, estando vulneráveis aos efeitos da subida do nível do mar (NM) e aos eventos de mudanças climáticas (MCGRANAHAN; BALK; ANDERSON, 2007). Em termos de distância, 23\% da população mundial reside em uma estreita faixa de $100 \mathrm{~km}$ do mar (SMALL; NICHOLLS, 2003).

Assim, qualquer mudança que ocorra nos oceanos afetará de alguma forma estes ambientes e a população residente nestas áreas. A inundação pode ser uma das consequências desta elevação (NICHOLLS; HOOZEMANS; MARCHAND, 1999; CHURCH et al., 2013; COOPER et al., 2013; ANDERSON et al., 2018;), podendo causar imensos prejuízos, inclusive irreversíveis, como a perda de ecossistemas, de habitats, bem como de vidas humanas e animais e danos a infraestruturas (GORNITZ, 1991; NICHOLLS; CAZENAVE, 2010).

As frequências e proporções das inundações podem ser agravadas com a intensificação de alguns fenômenos meteorológicos como aumento nas taxas de precipitação, ocorrência de marés meteorológicas, aumento do galgamento (run-up), dentre outros (DIEZ; ESTEBAN; PAZ, 2011), sendo um grande desafio prever estes eventos, e, cujos efeitos estão relacionados a uma dada probabilidade de ocorrência (BONETTI et al., 2013).

No Brasil 60\% da população reside nas áreas costeiras (PBMC, 2016) e, ainda assim, as pesquisas relacionadas à inundações costeiras são escassas sendo que deveriam ter um maior incentivo. Principalmente no litoral sul do país, cujo estado do Rio Grande do Sul (RS) é uma das áreas mais suscetíveis e vulneráveis à subida do mar, isto por ser uma planície costeira extensa, de baixa declividade e em meio a um sistema complexo de lagoas costeiras (HORN FILHO et al., 1988; DILLENBURG et al., 2016). Os municípios costeiros Imbé e Tramandaí, apresentam 19\% da população que vive no litoral norte do RS (IBGE, 2018). Os danos que esta intensa urbanização causa aos ecossistemas costeiros reduzem a capacidade de proteger a costa contra eventos extremos.

As elevações do nível d'água consideradas neste estudo consistem na soma das oscilações mareais e sub-mareais. As primeiras são aquelas controladas pelas forças gravitacionais astronômicas e as segundas, também denominadas como ressacas, são geradas por fenômenos meteorológicos. O estudo do efeito do galgamento é um dos importantes elementos para analisar a vulnerabilidade à erosões e inundações na costa, sendo composto de uma superelevação do nível médio da água causada pela quebra das ondas (set-up) e de flutuações pelo espraiamento na pós praia (swash) (HOLMAN; SALLENGER, 1985). Ou seja, estes processos induzem uma sobre-elevação do nível da água no litoral (BATTJES; JANSSEN, 1978).

Recentemente Vitousek et al. (2017) utilizaram modelagem numérica e diferentes cálculos para uma análise global das inundações costeiras nas próximas décadas devido ao aumento do NM, confirmando que um aumento de 10 a $20 \mathrm{~cm}$ até 2050 pode dobrar a frequência de eventos extremos, com prejuízos diretos à economia e à habitabilidade. As mudanças à níveis locais podem diferir, por uma série de fatores, das mudanças de níveis globais, portanto para o planejamento e adaptação as avaliações localizadas devem ser críticas (STAMMER et al., 2013; KOPP et al., 2014).

Um fator agravante no processo de inundação é o aumento do NM. A partir de resultados de modelos climáticos globais, para 2100 se espera, em média, um aumento do NM mínimo de 0,45 m, utilizando para tanto os dados do período de 1986 a 2005, com máximo em $0,82 \mathrm{~m}$ para o cenário mais pessimista (IPCC, 2014).

Seja hidrodinâmico, morfológico, ou ecológico, os impactos do aumento do NM estão interrelacionados e, assim, os gestores das zonas costeiras necessitam de informações e dados sobre estes efeitos potenciais para tomada de decisões (PASSERI et al., 2015). Para Barragán (2014), duas questões principais devem ser integradas na gestão costeira: a manutenção do bem-estar mútuo entre a sociedade e as áreas costeiras a longo prazo e, a adoção de um modelo de governança para se alcançar o proposto. Portanto, é momento de realizar uma gestão das zonas costeiras em união de órgãos governamentais, universidades, setores imobiliários e comunidade em geral.

Sendo assim, no presente estudo foram selecionadas duas áreas na região costeira do RS que passaram 
por processos de evolução costeira parecidos, que possuem características oceanográficas, meteorológicas e geológicas muito semelhantes, porém apresentam diferenças com relação a ocupação e proteção costeira. Ao se observar alguns eventos extremos de mar ocorridos na região de estudo, ficaram estabelecidas as seguintes indagações: Que áreas estão sujeitas a inundações? Como o aumento do NM pode afetar a população dos municípios de Tramandaí e Imbé? Quais ecossistemas serão afetados?

Assim, com base no que foi exposto acima o presente artigo tem os seguintes objetivos: (1) mapear as áreas costeiras, no entorno da desembocadura da lagoa de Tramandaí, suscetíveis à inundação a partir do aumento do NM em somatório com outras variáveis; (2) realizar uma análise comparativa da inundação costeira entre Tramandaí e Imbé e (3) oferecer ferramentas, como mapas, e informações úteis para gestores costeiros.

\section{METODOLOGIA}

\section{1 Área de estudo}

\subsubsection{GEOLOGIA, CLIMATOLOGIA E OCEANOGRAFIA DA ÁREA DE ESTUDO}

Os municípios de Imbé e Tramandaí estão localizados no litoral norte do Rio Grande do Sul (RS) (Figura 1), com orientação preferencial NE-SW, se alongando por cerca de $23 \mathrm{~km}$ de costa. São expostos a condições oceanográficas e meteorológicas de forte dinâmica, sujeitos a potencial risco de tempestades (GUIMARÃES et al., 2015) e assim estando suscetíveis à inundações costeiras e ressacas. Ambos são delimitados por uma desembocadura lagunar, importante na drenagem de todo sistema hidrográfico costeiro, fixada por uma estrutura do tipo guia-corrente (SILVA; TOLDO JR; WESHENFELDER, 2017).

Figura 1 - Localização dos municípios de Imbé e Tramandaí, separados pelo canal lagunar da Lagoa de Tramandaí e a delimitação das áreas 1 a 4.

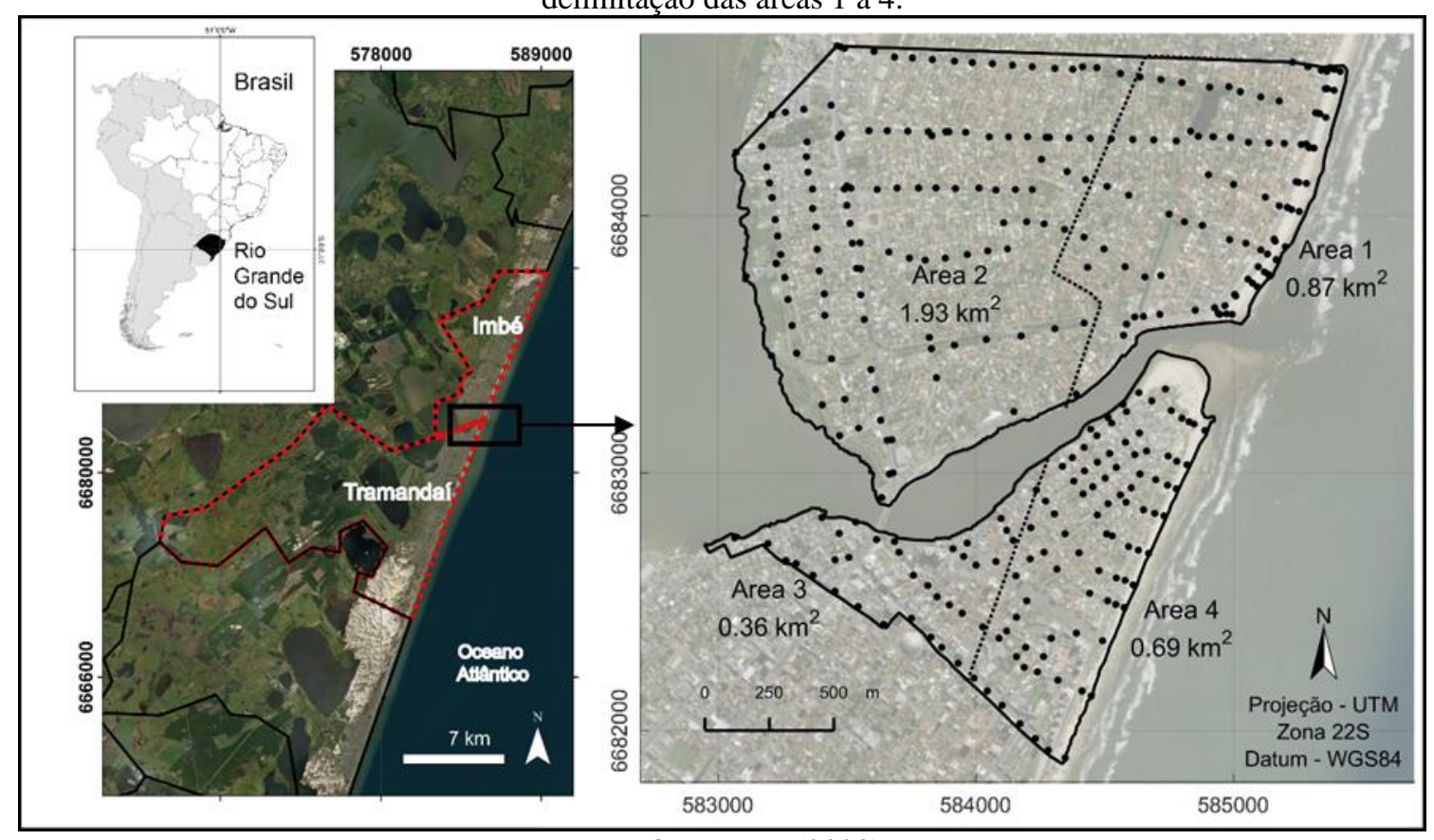

Fonte: Os autores (2020).

Hoje a população estimada para Imbé gira em torno de 22.309 pessoas, com densidade demográfica de 448,53 hab $/ \mathrm{km}^{2}$ e, Tramandaí com 50.760 pessoas e densidade demográfica de 287,97 hab/km² (IBGE, 2018). No verão, a população flutuante é de 40.427 pessoas em Imbé e 48.181 pessoas em Tramandaí (FEE, 2016).

Na região, o clima é subtropical úmido. Os ventos são controlados pelos sistemas de altas pressões tropicais e polares do Anticiclone Tropical do Atlântico Sul (ATAS) e do Anticiclone Polar Migratório (ATM) 
induzindo maior incidência dos ventos do quadrante nordeste entre os meses de setembro a março, e os ventos de sudoeste entre abril e agosto (NIMER, 1979).

Davies (1980) classifica a costa do RS como do tipo micromarés, com amplitude média de 0,25 m, podendo alcançar 1,20 m em uma maré meteorológica (ALMEIDA; ROSAURO; TOLDO JR, 1997). As ondulações que incidem sobre a costa do RS são geradas no oceano Atlântico sul e as vagas são provenientes de NE geradas pelos fortes ventos locais de verão e primavera. As ondas possuem direção predominante de SE e se caracterizam por energia de média a elevada, com altura significativa de $1,5 \mathrm{~m}$ e período entre 7 e $9 \mathrm{~s}$ (ALMEIDA; ROSAURO; TOLDO JR, 1997). Durante eventos de tempestade, a altura de onda em águas rasas pode exceder 2,5 m de altura com período de pico de $14 \mathrm{~s}$ (GUIMARÃES; FARINA; TOLDO, 2014). A profundidade de fechamento estimada é de 7,5 m (TOLDO et al., 2006).

Para avaliar o impacto da onda de tempestade sobre a costa de Imbé e Tramandaí, Guimarães et al. (2015) realizaram o cálculo do galgamento. Através do uso de modelos numéricos e medidas em campo, concluíram que durante eventos de tempestade ocorrem inundações em diversos locais em ambos municípios.

Toldo et al. (1993) classificaram, em relação à morfodinâmica, a praia de Imbé como praia intermediária a dissipativa e a praia de Tramandaí como dissipativa. Os sedimentos compreendem tamanho médio areia fina com extensa pós-praia, plana com baixa declividade.

É possível observar a preservação das dunas frontais em Tramandaí, fato que não ocorre em Imbé, no trecho de praia analisado neste estudo, onde sobre o sistema de dunas se encontram estruturas antrópicas, como implantação de avenida beira-mar e calçada.

\subsection{Materiais e métodos}

As projeções de aumento do NM se utilizam, principalmente, de dados de processos hidrodinâmicos. A metodologia descrita a seguir assume os dados mais críticos encontrados em processos regionais atuais quanto de possibilidades globais futuras, em vista de que no mínimo, com maior ocorrência de eventos extremos é possível ocorrer estes cenários de elevação do NM. A área de estudo foi separada por município para realização de descrição comparativa, bem como em quatro áreas para diferenciar os métodos aplicados.

\subsubsection{AQUISIÇÃO DOS DADOS}

\subsubsection{Dados topográficos - Método GNSS}

Para se obter os dados topográficos da área de estudo foi realizado um levantamento de campo entre os dias 3 e 5 de maio de 2016. A coleta foi executada utilizando o método GNSS (Global Navigation Satelite System). Para a geração do MDT (Modelo Digital de Terreno) os dados foram coletados utilizando um Receptor Geodésico de dupla frequência da marca Topcon Hiper Lite, método estático rápido. A qualidade dos dados, e consequentemente a acurácia das coordenadas são afetadas pelo tipo de receptor, método e tempo de rastreio e distância à base.

Um receptor base foi posicionado no marco geodésico do CECLIMAR/UFRGS (Centro de Estudos Costeiros, Limnológicos e Marinhos). O transporte de coordenadas planialtimétricas para este marco foi executado utilizando a estação POAL (Porto Alegre/ Departamento de Geodésia/ UFRGS). Foram medidas três séries de quatro horas cada uma, e a acurácia obtida foi de aproximadamente $0,021 \mathrm{~m}$.

A linha contínua (ver Figura 1) indica a área de estudo coletada pelo método GNSS e, corresponde a uma área de $2,8 \mathrm{~km}^{2}$ no município de Imbé (dividida em área 1 e 2) e $1,05 \mathrm{~km}^{2} \mathrm{em}$ Tramandaí (dividida em área 3 e 4). Os pontos escolhidos (ver Figura 1) para determinação das coordenadas foram preferencialmente os locais das ruas que continham bueiros, esquinas e outros pontos notáveis, sendo cada um rastreado por no mínimo 2 minutos, com taxa de rastreio de 1 segundo.

Posteriormente, os dados foram transferidos dos receptores para uma estação de trabalho e processados. Cada coordenada foi obtida utilizando o ajustamento de observações pelo método MMQ (Método 
dos Mínimos Quadrados). O programa utilizado foi o TOPCON TOOLS Versão 8.2. Todo o trabalho foi referenciado ao Sistema Geodésico SIRGAS 2000 (Sistema de Referência Geocêntrico para as Américas), e a projeção cartográfica utilizada foi a UTM (Universal Transversa de Mercator), fuso 22.

Para se transformar a altitude geométrica em ortométrica foi utilizada a Eq. (1) descrita abaixo:

$$
\mathrm{H}=\mathrm{N}-\mathrm{h}
$$

onde h é a altitude geométrica (m), H é a altitude ortométrica (m) e N é a ondulação geoidal (m).

A ondulação geoidal (N) de cada posição foi obtida através do modelo global MAPGEO2015 (IBGE, 2015).

Nos mapas, para representar o método GNSS, o aumento do nível se deu na forma de pontos, demonstrando exatamente o nível de elevação no ponto coletado.

\subsubsection{Dados LIDAR}

Em julho de 2010, no litoral norte do RS foram obtidos dados brutos a partir de um levantamento com equipamento de varredura LIDAR (Light Detection And Ranging) executado pela empresa LACTEC (Instituto de Tecnologia para o Desenvolvimento). O recobrimento LIDAR ocorreu com altura de voo de $1000 \mathrm{~m}$, com um ângulo de abertura de $20^{\circ}$ e densidade de 2 pontos por $\mathrm{m}^{2}$ (VIANNA; CALLIARI, 2015). Os arquivos XYZ (projetados em UTM, referenciados ao sistema SIRGAS $2000 \mathrm{com}$ altitudes referenciadas ao elipsoide) foram processados no software ALDPAT versão 1.0 e posteriormente foram produzidos Modelos Digitais de Superfície (MDS) que passaram por processo de conversão de altitudes geométricas para ortométrica, referenciadas ao geóide. Os arquivos foram disponibilizados para o presente trabalho por Vianna e Calliari (2005). A linha tracejada (ver Figura 1) indica a área de estudo coberta pela extensão do conjunto de dados LIDAR utilizada neste artigo, sendo de $0,87 \mathrm{~km}^{2}$ a área coberta no município de Imbé (área 1) e 0,69 km² em Tramandaí (área 4).

O nível do mar com o método LIDAR foi representado, nos mapas, através de buffer ("manchas coloridas").

\subsubsection{DEFINIÇÃO DOS CENÁRIOS DE INUNDAÇÃO}

Para determinação da cota de inundação a serem mapeadas foram definidas duas condições principais divididas em cenários. Na primeira condição utilizamos dados de eventos extremos, com as condições atmosféricas e oceânicas atuais, extraídos de Guimarães et al. (2015). Os autores utilizaram os modelos WaveWatch III, SWAN e SWASH para modelar as ondas na região de Tramandaí. A partir dos dados dos modelos e com a utilização de estimativa empírica calcularam a amplitude vertical deste processo (wave runup).

Na segunda condição consideramos projeções futuras cujos dados foram retirados do quinto relatório de avaliação (AR5) do IPCC (Intergovernmental Panel on Climate Change) (IPCC, 2013). Se fez a opção pelo RCP8.5 (Representative Concentration Pathways) cujos valores de subida do nível do mar para um cenário otimista e pessimista são $0,28 \mathrm{~m}$ e $0,98 \mathrm{~m}$, respectivamente, até o ano de 2100 .

A partir disso os cenários de inundação foram criados, sendo que cada um corresponde a uma cota de inundação calculada (Tabela 1). A realização dos cálculos para se obter as cotas foi feita através da soma de níveis médios de água selecionados e das variáveis escolhidas, como galgamento e projeções futuras do nível médio do mar apresentadas pelo IPCC (2013) a partir das mudanças climáticas conforme Eq. (2).

$$
\mathrm{CI}=N A+E N A+G
$$

onde CI corresponde a cota de inundação (m), NA ao nível d'água de referência (m), ENA a elevação do nível 
d'água (m) e $\mathrm{G}$ ao galgamento (m).

Os valores das cotas de inundação foram sobrepostos ao MDT para comparação das cotas altimétricas e observação das potenciais áreas de inundação costeira. Para criação dos mapas de inundação uma imagem do software Google Earth® foi sobreposta ao MDT facilitando a visualização e a compreensão das possíveis áreas a serem inundadas.

Tabela 1 - Valores utilizados para obtenção das cotas de inundação (* De acordo com IPCC (2013). ** De acordo com Guimarães et al. 2015).

\begin{tabular}{cccccc}
\hline Condição & Cenários & $\begin{array}{c}\text { Nível Médio } \\
\text { do Mar (m) }\end{array}$ & $\begin{array}{c}\text { Elevação do Nível } \\
\text { d'Água(m) } * *\end{array}$ & $\begin{array}{c}\text { Galgamento (m) } \\
* *\end{array}$ & $\begin{array}{c}\text { Cota de } \\
\text { Inundação (m) } \\
* *\end{array}$ \\
\hline Atual & 1 & 0 & 0,71 & 1,36 & 2,07 \\
& 3 & 0 & 0,76 & 1,65 & 2,41 \\
& 4 & 0 & 0,83 & 1,83 & 2,66 \\
\hline $\begin{array}{c}\text { Futuro } \\
\text { otimista }\end{array}$ & 5 & 0 & 0,84 & 1,04 & 3,35 \\
\hline $\begin{array}{c}\text { Futuro } \\
\text { pessimista }\end{array}$ & 7 & 0,28 & 1,38 & 1,97 & 3,63 \\
\hline
\end{tabular}

Fonte: Adaptada de Guimarães et al. (2015).

O modelo utilizado para representar as inundações no presente trabalho é considerado um "modelo banheira" ou "modelo de inundação" baseado em GIS (Geographic Information System) podendo ser definido como a projeção de uma superfície de inundação em um MDT, sendo fácil de implementar e fornece a especificidade espacial necessária (ANDERSON et al., 2018).

Este tipo de modelo - modelagem por inundação estática ou método estático - é uma alternativa simples para mapeamento de inundação costeira à modelagem hidrodinâmica, pois simplesmente se baseia em uma comparação de nível da água até a elevação do solo. A suposição é que a terra abaixo do nível do oceano é inundada instantaneamente e requer apenas o uso de um DTM (Digital Terrain Model) representando o terreno da área de interesse (GALLIEN et al., 2014).

A descrição de cada cenário será apresentada de acordo com cada cota de elevação encontrada, bem como dividida nas quatro áreas citadas acima (ver Figura 1) para que possamos descrever com maior exatidão as particularidades de cada local.

\section{RESULTADOS}

\subsection{Identificação das áreas vulneráveis à inundação}

Aqui ressaltamos que as cotas de inundação foram sobrepostas às cotas altimétricas do terreno, ou seja, a interação que possa existir entre a água e o sedimento ou, tipo de solo ou, estruturas rígidas não foi considerada. Tampouco foi avaliado os efeitos da água que podem ocorrer através do canal de Tramandaí.

\subsubsection{APLICAÇÃO DOS CENÁRIOS DO MODELO ATUAL}

Os resultados da elevação do NM, considerando as condições atmosféricas e oceânicas atuais, cujos dados foram extraídos de Guimarães et al. (2015), estão representados nos cenários 1 a 5 e seguem descritos abaixo. Os locais que apresentaram inundação costeira podem ser visualizados nas Figuras 2 a 4, representando cada cenário individualmente. 


\subsubsection{Cenário 1 - Elevação do Nível do Mar em 2,07 m}

Ao analisarmos a sobreposição dos dados podemos observar que a elevação do NM de 2,07 m foi suficiente para deixar o pós-praia submerso praticamente em toda a extensão das Áreas 1 e 4, salvo alguns trechos adjacentes ao muro do calçadão anexo à Avenida Beira Mar na Área 1 (Imbé), sendo que estes trechos foram identificados no método GNSS (Figura 4). Ainda na mesma área foi possível perceber que todas as ruas, calçadas e praticamente todos os imóveis ficaram inundados. A Área 2 (Imbé) é a que apresenta maiores trechos com ruas, calçadas e imóveis salvos à inundação com esta cota.

Na Área 3 (Tramandaí) apenas nos arredores da Prefeitura Municipal não ocorrerá inundação dos imóveis. Na Área 4 (Tramandaí) as ruas, calçadas e imóveis sobre o pontal arenoso de Tramandaí (considerado aqui a partir da rua Ubatuba de Farias para o norte) ficaram alagados, com exceção de pequenos trechos ao norte e sul da Avenida Beira Mar, e sudoeste da área. As regiões situadas nas margens e adjacências da lagoa, em todas as quatro áreas ficam alagadas. Todo trecho de dunas apresenta nível topográfico superior a esta cota de elevação. Cerca de 61,63 \% dos pontos levantados com o método GNSS, em toda área de estudo, apresentaram inundação com a cota de $2,07 \mathrm{~m}$.

\subsubsection{Cenário 2 - Elevação do Nível do Mar em 2,41 m}

A Figura 3 ilustra a elevação do nível do mar de 2,41 m, o qual provoca inundação em toda porção do pós-praia e áreas adjacentes à praia e desembocadura na Área 1. Poucos pontos levantados com a metodologia GNSS apresentaram níveis topográficos superiores à esta cota nesta área e se situam principalmente sobre o calçadão. Na Área 2 praticamente todas as ruas ficaram inundadas, bem como todos os imóveis ficam vulneráveis à inundação costeira, com exceção da Avenida Paraguassu e adjacências e, rua Santa Maria.

Figura 2 - Imagem ilustrando elevação do nível do mar em 2,07 m. As cores representam o nível de inundação (m) nos pontos (método GNSS) e manchas (buffer) (método LIDAR).

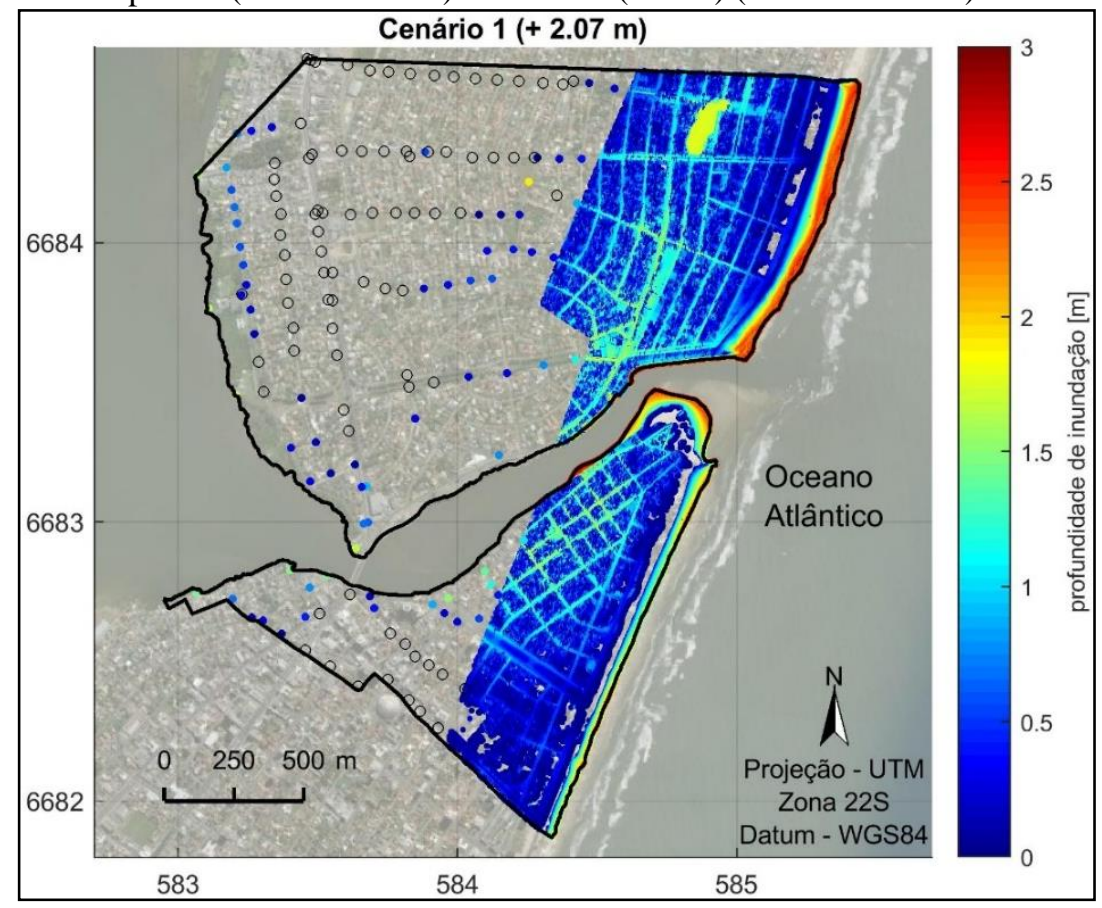

Fonte: Os autores (2020).

Na Área 3 as regiões que se apresentam inundadas com esta cota são semelhantes a elevação anterior. $\mathrm{Na}$ Área 4 se pode perceber pequenos pontos no norte e no sul da Avenida Beira Mar que não ficam inundados. Cerca de 75,23\% dos pontos levantados com o método GNSS, em toda área de estudo, apresentaram inundação com a cota de $2,41 \mathrm{~m}$. 


\subsubsection{Cenário 3 - Elevação do Nível do Mar em 2,66 m}

Com a cota de inundação de 2,66 m apenas a partir da metodologia GNSS foi possível de se constatar pontos com cotas acima deste valor na Área 1 que não estariam cobertas pela inundação sendo localizadas na região do calçadão. Na Área 2 destacamos ausência da inundação nos locais similares aos citados na cota anterior. $\mathrm{Na}$ Área 3 se percebe inundação em um maior trecho próximo à prefeitura Municipal de Tramandaí e na Área 4 apenas a região superior das dunas não se apresenta inundada. Cerca de $82,17 \%$ dos pontos levantados com o método GNSS, em toda área de estudo, apresentaram inundação com a cota de 2,66 m.

Figura 3 - Imagem ilustrando elevação do nível do mar em 2,41 m. As cores representam o nível de inundação (m) nos pontos (método GNSS) e manchas (buffer) (método LIDAR).

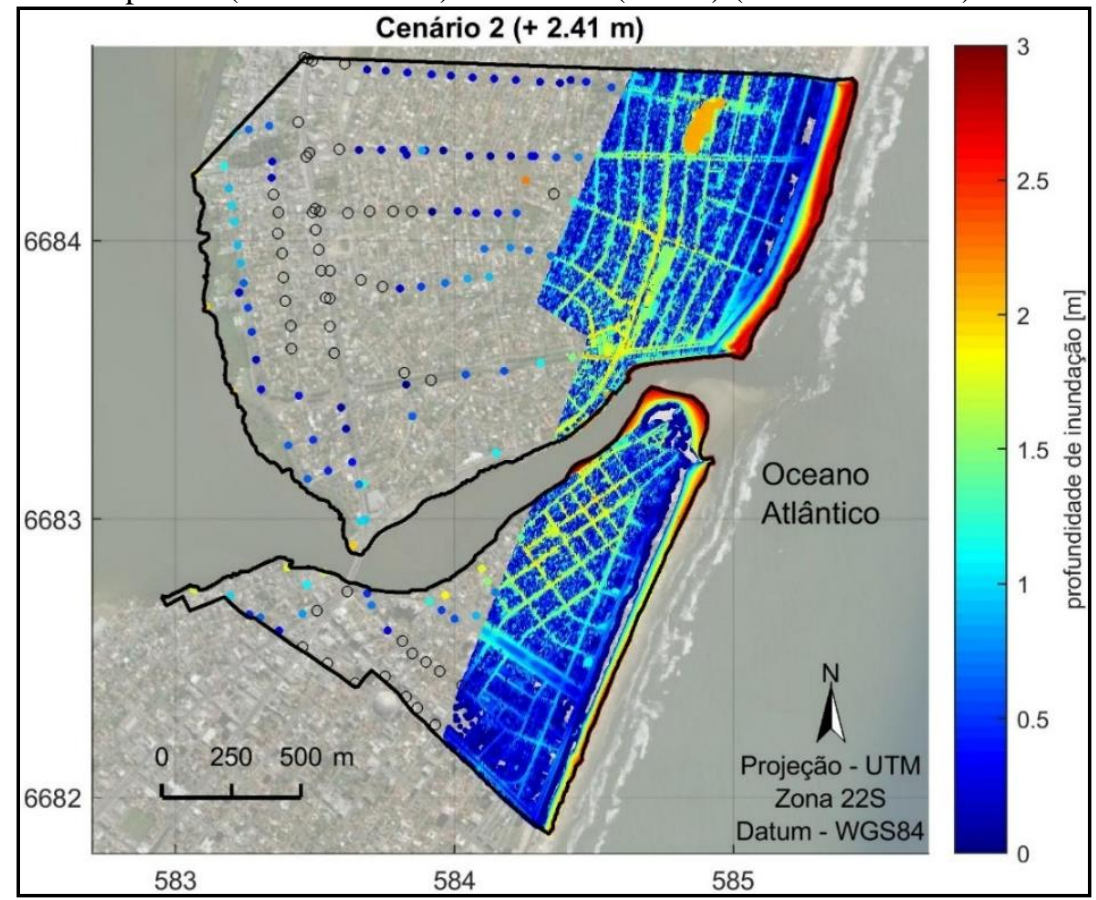

Fonte: Os autores (2020).

\subsubsection{Cenário 4 - Elevação do Nível do Mar em 2,88 m}

Na elevação do nível do mar de 2,88 m se visualiza toda Área 1 inundada (novamente destacamos que apenas ao comparar o método GNSS é que se observam pontos com altimetria superior a esta presente cota). Na Área 2 praticamente todas as ruas, calçadas e imóveis se apresentam inundados com poucos trechos na Avenida Paraguassu livres desta inundação. A Área 3, levantada, se encontra toda inundada. Já na Área 4 apenas a porção superior das dunas se apresentam escapes à inundação. Cerca de $89,12 \%$ dos pontos levantados com o método GNSS, em toda área de estudo, apresentaram inundação com a cota de 2,88 m.

\subsubsection{Cenário 5 - Elevação do Nível do Mar em 3,35 m}

Na Área 1 com a elevação do nível do mar em 3,35 m se observa inundação em toda área (Figura 4). $\mathrm{Na}$ Área 2 apenas 6 pontos apresentam cota acima deste valor. Ambas as Áreas 3 e 4 ficam totalmente inundadas exceto a porção superior das dunas na Área 4. Cerca de 94,86\% dos pontos levantados com o método GNSS, em toda área de estudo, apresentaram inundação com a cota de 3,35 m. 
Figura 4 - Imagem ilustrando elevação do nível do mar em 3,35 m. As cores representam o nível de inundação (m) nos pontos (método GNSS) e manchas (buffer) (método LIDAR).

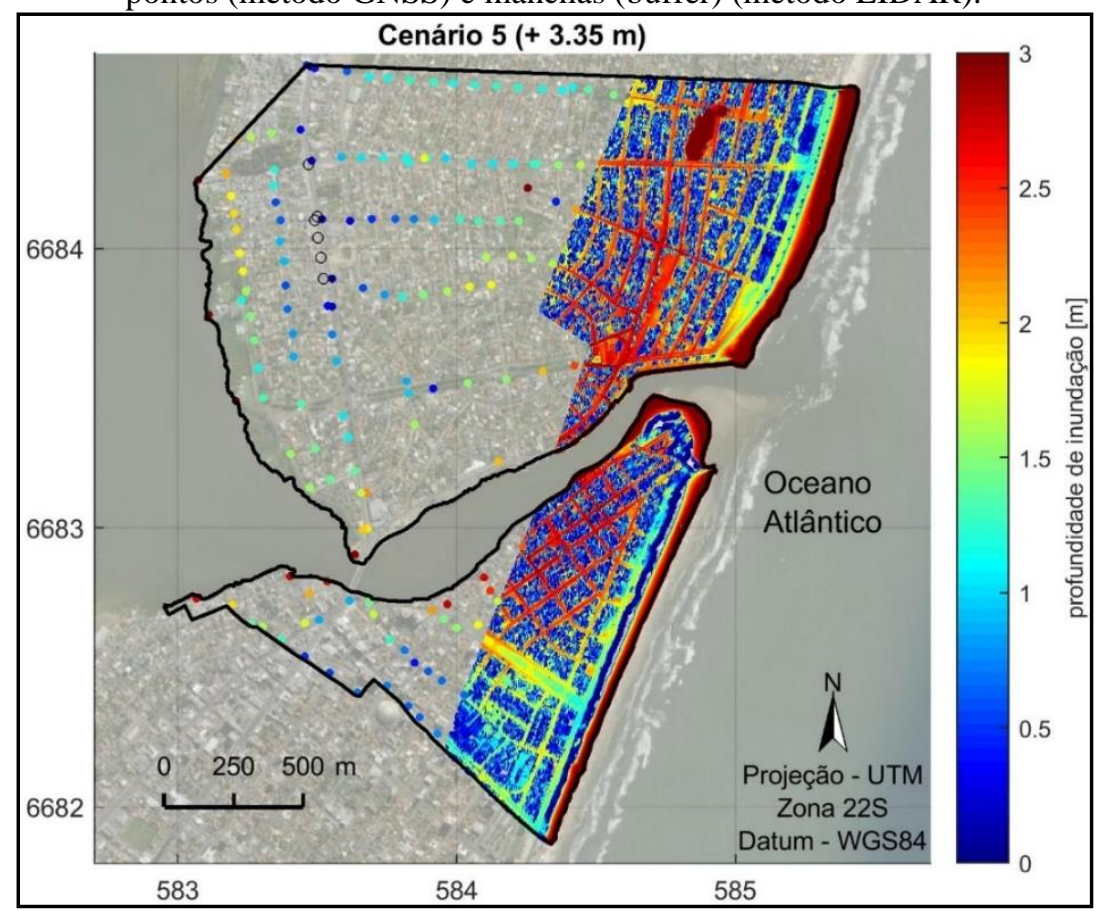

Fonte: Os autores (2020).

\subsubsection{APLICAÇÃO DOS CENÁRIOS DO MODELO COM AS MUDANÇAS CLIMÁTICAS}

A partir da análise dos dados foi possível observar que a elevação do nível do mar de ambos os cenários 6 e 7 apresentaram os mesmos resultados em termos de extensão de inundação, ou seja, tanto a cota de 3,63 m quanto de 4,33 m deixam todas as Áreas 1, 2 e 3 inundadas e, na Área 4 apenas o trecho da porção superior das dunas não apresenta inundação. Cerca de 97,28 \% dos pontos levantados com o método GNSS, em toda área de estudo, apresentaram inundação com ambas as cotas.

A Figura 5 apresenta a inundação costeira que ocorre no cenário 7 no qual foram consideradas as condições futuras atmosféricas e oceânicas, projetadas de acordo com o IPCC (2013), até o ano de 2100 , somada às demais variáveis escolhidas conforme a Tabela 1. 
Figura 5 - Imagem ilustrando elevação do nível do mar em 4,33 m. As cores representam o nível de inundação (m) nos pontos (método GNSS) e manchas (buffer) (método LIDAR).

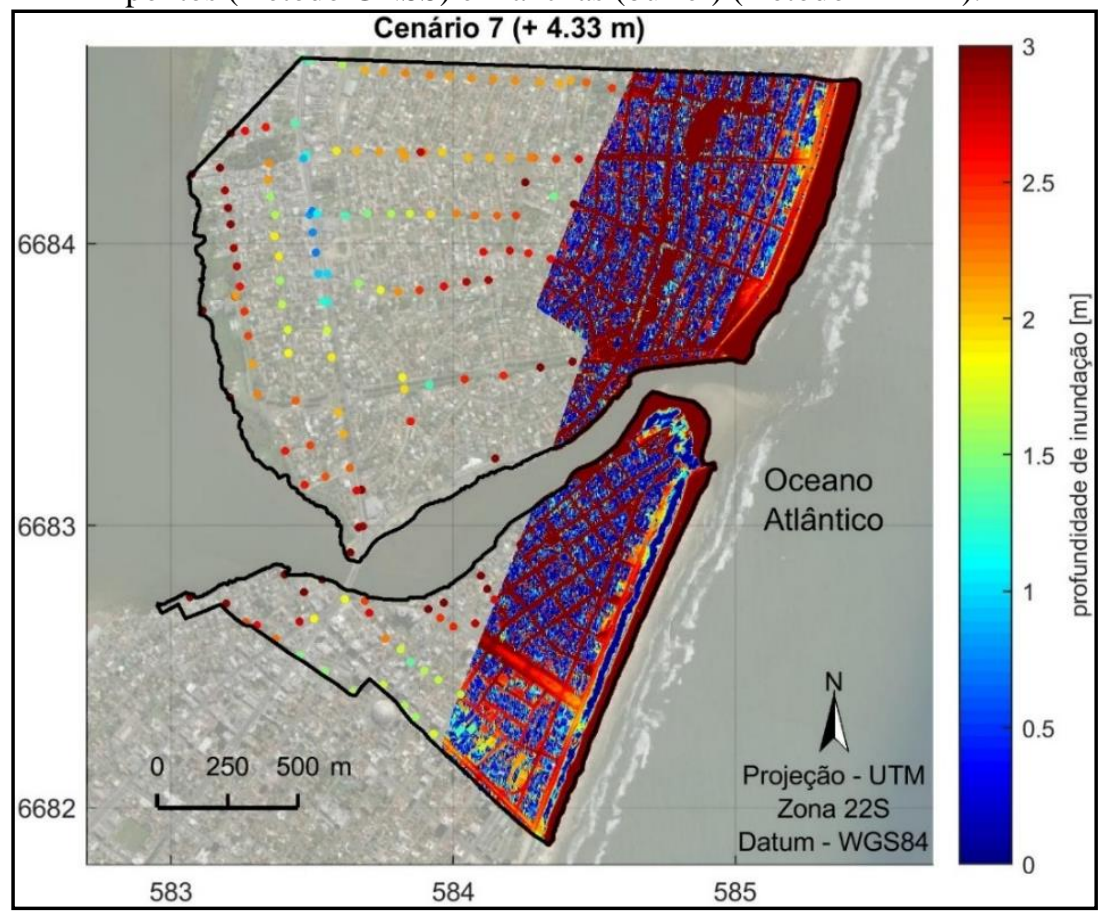

Fonte: Os autores (2020).

\section{DISCUSSÃO}

A presente análise multidisciplinar de inundações costeiras difere da maioria das outras pesquisas em termos (1) dois métodos de aquisição de dados topográficos (GNSS e LIDAR) e (2) comparação entre dois municípios separados por uma desembocadura, beneficiando as observações da extensão de inundação para futuras possíveis decisões de gestão costeira.

Através de mapas de inundação elucidamos as possíveis áreas a serem afetadas com diferentes taxas de elevação do NM. A determinação das áreas vulneráveis à inundação foi baseada em informações topográficas, onde as áreas inferiores ao NM teórico à elevação foram inundadas, partindo do pressuposto que a representatividade dos mapas de inundação depende da qualidade dos dados utilizados e da aplicação da metodologia adequada (RAJI et al., 2011).

\subsection{Avaliação da vulnerabilidade das áreas submetidas à inundação}

No presente estudo, a união dos dados topográficos de alta resolução do LIDAR em conjunto com o método GNSS permitiram obter um modelo de inundação realista, e também, a avaliação de impactos potenciais (GESCH, 2009). Os dados de elevação do terreno obtidos com LIDAR foram de elevada qualidade para identificar e delinear determinadas áreas vulneráveis à subida do NM, fato igualmente observado por Heberger et al. (2009), Wadey et al. (2015) e Gallien (2016).

Diferenças encontradas entre os dois métodos não foram significativas e isso pode ter ocorrido devido à distância obtida entre os pontos serem diferentes nos métodos.

A aplicação das cotas de inundação, na qual utilizamos dados de galgamento pela fórmula de Stockdon et al. (2006) (GUIMARÃES et al., 2015) também foi utilizada por Gallien (2016) para avaliar a vulnerabilidade à inundação costeira na Califórnia, sendo uma das medidas centrais para os esforços de mapeamento de inundação. Os resultados deste trabalho mostram que uma elevação de 2,07 m (cenário 1) é suficiente para inundar grande parte das ruas, calçadas e imóveis de ambos os municípios, além de deixar toda a infraestrutura disponível vulnerável a este processo. Takagi et al. (2016) citam que uma área inundada a uma profundidade de $1 \mathrm{~m}$ ou mais pode ser considerada perigosa, sendo esperados danos substanciais nos assentamentos humanos 
e seus habitantes.

Esta cota de elevação representada no cenário 1 poderá também penetrar através dos bueiros e sistemas de esgoto e introduzir ainda mais água salgada nas áreas urbanas. Os maiores impactos são observados na região do pontal arenoso de Tramandaí (Área 4), bem como nas residências das margens da lagoa e na Área 1. Guimarães et al. (2015) demonstraram inundação nas mesmas áreas com valores de cota de inundação menores que 2,07 m citando ainda que a Área 1 seria a mais vulnerável a processos de overtopping visto que não apresenta região de dunas, sendo este resultado coincidente com a presente pesquisa. Maiores inundações em áreas de maiores perdas sedimentares também foram encontradas por Gagliardi (2013) na desembocadura de Cananéia (SP), sendo áreas que primeiro sofreriam inundação.

Com a diferença da cota de inundação entre o cenário 1 e 5 observamos um aumento pronunciado em número de propriedades impactadas, o que também pode ocasionar problemas na rede de esgoto e drenagem, além de que as estradas ao redor do centro da cidade se tornariam intransitáveis $(0,3 \mathrm{~m}$ de água corrente é capaz de mover um carro médio (WADEY et al., 2015)). Os processos geológicos que ocorreram na formação e evolução de toda esta região tornaram-na suscetível à inundação por ter baixa altimetria e, a população que ocupou este local sem conhecimento de seus processos ficou assim exposta a este risco.

\subsection{Diferenças entre Imbé e Tramandaí}

Tramandaí apresentou um maior nível de inundação o que nos indica ser uma região com relevo menor que Imbé, sendo o pontal de Tramandaí (desconsiderando as dunas e as margens da lagoa) a região mais baixa de toda área da pesquisa. Isto pode ser devido ao fato de que esta região era estuarina até a ocupação se adensar sobre este ambiente. Já em Imbé, as áreas com menores níveis topográficos se situam na região do Braço Morto. A ocupação que ali se estabeleceu se encontra vulnerável por estar sobre uma região baixa, área de um antigo canal.

Com a cota de inundação do cenário 1 praticamente 57\% e 70\%, respectivamente, de Imbé e Tramandaí apresentam inundações, ou seja, com a menor cota de inundação aqui testada temos uma alta vulnerabilidade na área. Ao analisarmos os cenários 5 a 7 percebemos que praticamente toda região de estudo fica inundada exceto as porções superiores das dunas em Tramandaí. Em Imbé, todo o sistema de dunas foi removido para construção da Avenida Beira Mar e calçadão na década de 1980. O modelo apresentado neste trabalho não nos permite afirmar que Tramandaí estaria mais protegido por manter seu sistema de dunas preservado, embora mencionado por Guimarães et al. (2015). Hesp (1988) e Larson et al. (2004) citam as dunas como função de proteção costeira, fato comprovado por Martelo e Nicolodi (2018) na praia do Mar Grosso (RS).

A inundação que observamos nos cenários 1 a 7, além das implicações já citadas anteriormente, pode afetar a economia de ambos os municípios, como por exemplo, em Imbé junto a margem fixada existe um terminal marítimo da Petrobrás, que também ficaria prejudicado, bem como ocorreriam mudanças na desembocadura modificando as atividades dos pescadores.

Imbé fica defronte às primeiras reações do mar, com ocorrência de galgamento sobre as estruturas construídas na orla (GUIMARÃES et al., 2015), fato também observado no Rio de Janeiro (MANDARINO; ARUEIRA, 2012) e na praia do Hermenegildo (RS) (MAIA; CALLIARI; NICOLODI, 2016). Além do galgamento, eventos ocasionados por marés de sizígia podem provocar "afogamento" das galerias de águas pluviais, o que gera inundações em áreas baixas como no pontal de Tramandaí já identificadas in situ pelos presentes autores.

Observamos também uma maior concentração da ocupação justamente ao longo das margens do canal de Tramandaí, ficando essas construções suscetíveis a possíveis danos de inundação e contrapondo a Lei nº 4771/65. A não ocupação destas áreas auxiliaria principalmente na diminuição de sua vulnerabilidade. As propriedades localizadas sobre o aterro de áreas de banhados e nas adjacências, em ambos os municípios, principalmente em toda região do Braço Morto (Imbé) se tornam mais suscetíveis se considerarmos o aumento de nível de água através do lençol freático, por serem áreas mais baixas.

Após este enfoque na inundação costeira e por perceber que pode ser apenas uma das implicações das 
mudanças climáticas fica visível a necessidade de mudanças no estilo de vida e na visão de como estamos utilizando os recursos naturais.

As zonas costeiras com baixa declividade e descaracterização dos ecossistemas naturais tem a tendência de serem mais vulneráveis à inundação costeira, seja ela por eventos atmosféricos pontuais ou por mudanças climáticas futuras. A importância de se conhecer a dinâmica de um ambiente, seu funcionamento ao longo de anos e identificar as áreas vulneráveis a possíveis inundações devido à elevação do NM se faz necessário para uma eficiente gestão costeira, pois assim haverá uma melhor distribuição da ocupação, uma maior segurança para estas comunidades e uma maior proteção para os ecossistemas devido toda sua importância ecológica.

É importante ressaltar que o "modelo banheira" utilizado nesta pesquisa pode ignorar áreas possíveis de serem inundadas (ANDERSON et al., 2018), subestimar os valores de inundação por não simular os efeitos de atenuação do fluxo devido à vegetação, bueiros, etc. (RODRIGUEZ et al., 2017), bem como superestimar os valores de inundações, fato encontrado por Gallien et al. (2014) ao analisarem a extensão de inundação coletadas após o evento de sobreposição de maré.

Reconhecemos a simplicidade deste modelo para identificação das áreas vulneráveis à inundação, apesar disso, conseguimos obter uma ideia sobre a área total que poderá ser inundada caso ocorra um evento de aumento do NM, bem como as áreas mais vulneráveis à determinadas cotas de inundação, corroborando com a ideia de Heberger et al. (2009) quanto a utilidade deste modelo estático para aumentar a conscientização sobre os impactos de longo prazo da elevação do NM.

Como entrada de variáveis nós utilizamos dados de processos hidrodinâmicos, porém outras informações importantes como tempo da inundação, tipo do solo, erosão costeira, avaliação na mudança da linha de costa, overtopping, overwash e entrada de água pelo canal não foram analisados. Tal abordagem não considera a conectividade hidrológica às células da grade oceânica próximas (POULTER; HALPIN, 2007), o qual este conhecimento seria muito importante aja vista as ressacas que ocorrem na região, transpassando as estradas, bem como a presença da desembocadura lagunar, podendo aumentar o espelho d'água em toda a laguna.

Em resumo, esta pesquisa demonstrou eficácia na utilização de dados altimétricos para elaboração de mapas de inundação costeira com vista a visualização e determinação de áreas vulneráveis à elevação do nível do mar. Embora o modelo utilizado possua suas limitações e não aborde determinadas variáveis importantes no que tange a inundação, se mostrou eficaz para o objetivo do presente estudo e para utilização de futuros estudos e decisões costeiras.

\section{CONCLUSÕES}

Os municípios de Imbé e Tramandaí devido às suas configurações geológicas (zona costeira com exposição à dinâmica oceânica) e sua atual intensa ocupação (altas taxas de densidade demográfica), se apresentam como uma região altamente vulnerável a um aumento do NM. A topografia é um elemento chave à suscetibilidade dos processos físicos ativos que ocorrem ao longo da costa e seu conhecimento e representação na forma de modelos digitais de elevação fornecem um importante conjunto de dados para analisarmos a inundação costeira.

As inundações costeiras irão ocorrer quando da somatória de algumas variáveis como por exemplo, maré astronômica e galgamento. A partir da soma destas duas variáveis, com uma cota de inundação encontrada de $2,07 \mathrm{~m}$ aproximadamente $0,87 \mathrm{~km}^{2}$ da área de Imbé e $0,69 \mathrm{~km}^{2}$ de Tramandaí já são impactadas com alagamentos e, pode ocorrer inundação em praticamente $62 \%$ dos arredores da desembocadura de Tramandaí, incluindo ruas, calçadas e estruturas construídas, além dos ecossistemas ali presentes. Com uma cota de inundação de 3,35 m este valor aumenta para 95\% e a inundação costeira impacta cerca de $2,8 \mathrm{~km}^{2}$ do município de Imbé e, 1,05 km² de Tramandaí, ou seja, apenas a região do topo das dunas de Tramandaí fica emersa.

Um evento meteorológico que pode ocorrer casualmente pode causar a mesma inundação e impactar diversas propriedades tanto quanto uma possível elevação do nível do mar daqui há 100 anos. Assim, uma cota 
de inundação de 3,35 m com condições atmosféricas e oceânicas atuais propiciam consideravelmente intensa inundação nas áreas do estudo quanto uma cota de 4,33 m projetada para um futuro aumento do NM.

Dados topográficos de alta qualidade como LIDAR permitem um avanço significativo no mapeamento das inundações costeiras em potencial. Integrados com medidas do método GNSS fornecem informações detalhadas e precisas da altimetria de uma determinada região para aplicações críticas, como modelagem de elevação do nível do mar. O modelo de inundação aqui elaborado a partir desses dados e a representação dos cenários contribuiu para uma compreensão das áreas potenciais que podem ser direta ou indiretamente afetadas.

A visualização das diferenças encontradas entre os municípios de Tramandaí e Imbé se faz necessária para que possamos perceber quais áreas da região estão mais suscetíveis, o quanto a verticalização de um local o torna mais vulnerável, bem como compreender que uma ocupação mal planejada e com descaracterização dos ecossistemas costeiros pode agravar a vulnerabilidade da comunidade que ocupou estes ambientes, além de maior exposição ao efeitos morfodinâmicos.

De caráter urgente e alta relevância é a continuação no desenvolvimento de diversas ferramentas, entre elas as modelagens hidrodinâmicas que, associadas com pesquisas de cunho científico demonstram quais áreas costeiras devem ter maior atenção e assim, evitar maiores danos aos ecossistemas e população.

No Brasil ainda não existe nenhum plano estratégico sobre mitigação, nem adaptação relacionado à inundação costeira. Esses planos poderiam auxiliar no retardo da degradação ambiental e na vulnerabilidade às inundações costeiras. Provavelmente, locais preservados, terão respostas diferentes devido às especificidades desse ecossistema, amortizando a vulnerabilidade.

Por mais que ainda não ocorreram grandes inundações significativas na região desta pesquisa se faz necessário a tomada de consciência por parte do poder público para que haja um planejamento em termos de avaliação e mapeamento das áreas sujeitas a estes tipos de impactos e métodos precisos de mitigação. As imagens de inundação aqui elaboradas podem ser um guia para priorizar ações de planejamento e tomar decisões para administrar de forma adaptável os impactos do aumento do NM.

Novas pesquisas são sugeridas no âmbito da modelagem hidrodinâmica, no qual acrescente variáveis aqui não analisadas (acima citadas) tanto para comprovação das proteções à inundação costeira pela presença de dunas quanto com relação ao período de tempo necessário para uma área ficar inundada e poder levar à evacuação oportuna de pessoas (resposta); coletas de dados locais de séries temporais de observação (como mudança do nível do mar); cálculo das áreas potenciais de inundação e a valoração das estruturas que podem ser atingidas.

\section{Agradecimentos}

Os autores agradecem a João Henrique Quoos, José Carlos R. Nunes, Júlio de Oliveira Fernandes, Pedro Veras Guimarães e Rafael Muller Petermann, pelos auxílios prestados durante a elaboração desta pesquisa.

\section{Contribuição dos Autores}

Conceptualização: A.F.S., E.E.T.J., A.V.R., C.F.A.; Curadoria dos dados: A.F.S., R.S.R., R.S.A.; Análise formal: A.F.S., A.V.R., J.L.R.F.; Investigação: A.F.S., R.S.R., R.S.A.; Metodologia: A.F.S., A.V.R., C.F.A., R.S.R.; Redação: A.F.S., E.E.T.J., C.F.A., J.L.R.F; Minuta inicial: A.F.S., J.L.R.F.; Aquisição de financiamento: E.E.T.J.; Recursos: E.E.T.J.; Supervisão: A.F.S.; Software: A.V.R.; Revisão: A.F.S., E.E.T.J., C.F.A., J.L.R.F.; Visualização: A.V.R.; Edição: A.F.S., C.F.A., J.L.R.F.

\section{Conflito de Interesse}

Os autores declaram que não há conflito de interesse. 


\section{Referências}

ALMEIDA, L. E. S. B.; ROSAURO, N. M. L.; TOLDO JR., E. E. Análise Preliminar das Marés na Barra do Rio Tramandaí, RS. In: $12^{\circ}$ SIMPÓSIO BRASILEIRO DE RECURSOS HÍDRICOS, 1997, Vitória. Anais do $1^{\circ}{ }^{\circ}$ Simpósio Brasileiro de Recursos Hídricos, Vitória, 1997. p. 560-566.

ANDERSON, T. R.; FLETCHER, C. H.; BARBEE, M. M.; ROMINE, B. M.; LEMMO, S.; DELEVAUX, J. M. S. Modeling multiple sea level rise stresses reveals up to twice the land at risk compared to strictly passive flooding methods. Scientific Reports, v. 8, p. 14484, 2018. DOI: 10.1038/s41598-018-32658$\mathrm{x}$

BARRAGÁN, J. M. Política, gestão e litoral: uma nova visão da Gestão Integrada de Áreas Litorais. Madrid, Tébar Flores, 2014. 685 p.

BATTJES, J. A.; JANSSEN, J. P. F. M. Energy loss and set-up due to breaking of random waves. In: 16th INTERNATIONAL CONFERENCE ON COASTAL ENGINEERING, 1978, Hamburg. Proceedings American Society of Civil Engineers, 1978, p. 569-587. DOI: 10.1061/9780872621909.034

BONETTI, J.; KLEIN, A. H. F.; MULER, M.; DE LUCA, C. B.; SILVA, G. V.; TOLDO JR., E. E.; M. GONZÁLEZ. Spatial and numerical methodologies on coastal erosion and flooding risk assessment. In: FINKL, C. (ed.) Coastal Hazards. Chapter 16. Coastal Research Library Series. Springer, Dordrecht, 2013. p. 423-442.

CHURCH, J. A.; CLARK, P. U.; CAZENAVE, A.; GREGORY, J. M.; JEVREJEVA, S.; LEVERMANN, A.; MERRIFIELD, M. A.; MILNE, G. A.; NEREM, R. S.; NUNN, P. D.; PAYNE, A. J.; PFEFFER, W. T.; STAMMER, D.; UNNIKRISHNAN, A. S. Sea Level Change. In: CLIMATE CHANGE 2013: THE PHYSICAL SCIENCE BASIS. Cambridge University Press, Cambridge, NY, USA, 2013. p. 11371216.

COOPER, H. M.; FLETCHER, C. H.; CHEN, Q.; BARBEE, M. M. Sea-level rise vulnerability mapping for adaptation decisions using LIDAR DEMs. Progress Physical Geography, v. 37, p. 745-766, 2013. DOI: $10.1177 / 0309133313496835$

DAVIES, J. L. Geographical Variation in Coastal Development. Londres, Longman, 1980. 212p.

DIEZ, J. J.; ESTEBAN, M. D.; PAZ, R. Urban coastal flooding and climate change. Journal of Coastal Research, v. 64, p. 205-209, 2011.

DILLENBURG, S. R.; TOMAZELLI, L. J.; HESP, P. A.; BARBOZA, E. G.; CLEROT, L. C. P.; SILVA, D. B. Stratigraphy and evolution of a prograded barrier in southern Brazil. Journal of Coastal Research, v. 39, p. 132-135, 2006.

FEE. Fundação de Economia e Estatística. Estimativas para a população flutuante do Litoral Norte do RS. Porto Alegre, FEE, 2016. 29p.

GAGLIARDI, M. H. Análise de riscos costeiros a eventos atmosféricos extremos no litoral sul do Estado de São Paulo. Estudo de caso na região da desembocadura de Cananéia. São Paulo. 2013. 238p. Dissertação de Mestrado. Universidade de São Paulo, Programa de Pós Graduação em Ciências, Instituto Oceanográfico, São Paulo, 2013.

GALLIEN, T. W.; SANDERS, B.; FLICK, R. Urban coastal flood prediction: Integrating wave overtopping, flood defenses and drainage. Coastal Engineering, v. 91, p. 18-28, 2014. DOI: 10.1016/j.coastaleng.2014.04.007

GALLIEN, T. W. Validated coastal flood modeling at Imperial Beach, California: Comparing total water level, empirical and numerical overtopping methodologies. Coastal Engineering, v. 111, p. 95-104, 2016. DOI:10.1016/j.coastaleng.2016.01.014

GESCH, D. B. Analysis of Lidar elevation data for improved identification and delineation of lands vulnerable to sea-level rise. Journal of Coastal Research, v., 25, n. 6, p. 49-58, 2009. 
GORNITZ, V. Global coastal hazards from future sea level rise. Palaeogeography, Palaeoclimatology, Palaeoecology, v. 89, p. 379-398, 1991.

GUIMARÃES, P. V.; FARINA, L.; TOLDO, E. E. Analysis of extreme wave events in the southern coast of Brazil. Natural Hazards and Earth System Sciences, v. 2, n. 6, p. 4363-4391, 2014. DOI:10.5194/nhessd-2-4363-2014

GUIMARÃES, P. V.; FARINA, L.; TOLDO JR.; E. E., DIAZ-HERNANDEZ, G.; AKHMATSKAYA, E. Numerical simulation of extreme wave runup during storm events in Tramandaí Beach, Rio Grande do Sul, Brazil. Coastal Engineering, v. 95, p. 171-180, 2015. DOI:10.1016/j.coastaleng.2014.10.008

HEBERGER, M.; COOLEY, H.; HERRERA, P.; GLEICK, P. H.; MOORE, E. The Impacts of Sea-Level Rise on the California Coast. Sacramento, California Climate Change Center, 115p. 2009.

HESP, P. A. Surfzone, beach and foredune interactions on the Australian southeast coast. Journal of Coastal Research, v. 3, p.15-25, 1988.

HOLMAN, R. A.; SALLENGER JR, A. H. Setup and swash on a natural beach. Journal of Geophysical. Research, v. 90, p. 945-953, 1985.

HORN FILHO, N. O.; VILLWOCK, J. A.; DEHNHARDT, B. A.; TOMAZELLI, L. J.; DEHNHARDT, E. A.; LOSS, E. L.; BACHI, F. A.; GODOLPHIM, M. F. 1988. Mapeamento geológico da província costeira do Rio Grande do Sul. In: Anais do Simpósio Sobre Depósitos Quaternários das Baixadas Litorâneas Brasileiras: Origem, Características Geotécnicas e Experiências de Obras, Rio de Janeiro, 1988, v.2, p. 1-21.

INSTITUTO BRASILEIRO DE ECONOMIA E ESTATÍSTICA (IBGE). Modelo de Ondulação Geoidal. MAPGEO2015. Site <https://ww2.ibge.gov.br/home/geociencias/geodesia>, acessado em junho de 2016.

INSTITUTO BRASILEIRO DE ECONOMIA E ESTATÍSTICA (IBGE). Brasil em síntese. Site $<$ http://cidades.ibge.gov.br/>, acessado em novembro de 2018.

INTERGOVERNMENTAL PANEL ON CLIMATE CHANGE (IPCC). The Physical Science Basis, Contribution of Working Group I to the Fourth Assessment Report of the Intergovernmental Panel on Climate Change, In: Solomon et al. (eds.). Cambridge Univ. Press, Cambridge, 2007.

INTERGOVERNMENTAL PANEL ON CLIMATE CHANGE (IPCC). Summary for policy makers, in Climate Change 2013: The Physical Science Basis. (STOCKER et al. (eds.). Cambridge Univ. Press, U. K, 2013, 29p.

INTERGOVERNMENTAL PANEL ON CLIMATE CHANGE (IPCC). Climate Change 2014: Synthesis Report. Contribution of Working Groups I, II and III to the Fifth Assessment Report of the Intergovernmental Panel on Climate Change. (PACHAURI, R. K.; MEYER, L. A. (eds.). IPCC, Switzerland, 2014, 151p.

KOPP, R. E.; HORTON, R. M.; LITTLE, C. M.; MITROVICA, J. X.; OPPENHEIMER, M.; RASMUSSEN, D. J.; STRAUSS, B. H.; TEBALDI, C. Probabilistic 21st and 22nd century sea-level projections at a global network of tide-gauge sites. Earth's Future, v. 2, p. 383-406, 2014.

LARSON, M.; ERIKSON, L.; HANSON, H. An analytical model to predict dune erosion due to wave impact. Coastal Engineering, v. 51, p. 675-696, 2004.

LIESKE, D. J.; WADE, T.; RONESS, L. A. Climate change awareness and strategies for communicating the risk of coastal flooding: A Canadian Maritime case example. Estuarine, Coastal and Shelf Science, v. 140, p. 83-94, 2014.

MARTELO, A. F.; NICOLODI, J. L. As dunas frontais e sua função frente às inundações da costa: validação de dois modelos de erosão como ferramenta para a gestão costeira aplicados na praia do Mar Grosso, RS. Desenvolvimento e Meio Ambiente, v. 44, p. 223-241, 2018.

MAIA, N. Z.; CALLIARI, L. J.; NICOLODI, J. L. Analytical model of sea level elevation during a storm: 
Support for coastal flood risk assessment associated with cyclone passage. Continental Shelf Research, v. 124, p. 23-34, 2016.

MANDARINO, F. C.; ARUEIRA, L. R. Vulnerabilidade à elevação do nível do mar na Região Metropolitana do Rio de Janeiro. Estudos cariocas, 2012, p. 1-16.

MCGRANAHAN, G.; BALK, D.; ANDERSON, T. The rising tide: Assessing the risks of climate change and human settlements in low elevation coastal zones. Environment and Urbanization, v. 19, n. 1, p. 1737, 2007.

NICHOLLS, R. J.; HOOZEMANS, F. M. J.; MARCHAND, M. Increasing flood risk and wetland losses due to global sea-level rise: regional and global analyses. Global Environmental Change, v. 9, p. 69-87, 1999.

NICHOLLS, R. J.; CAZENAVE, A. Sea-level rise and its impact on coastal zones. Science, v. 328, p. 1517$1520,2010$.

NIMER, E. Climatologia do Brasil. Rio de Janeiro, IBGE, 1979. 421p.

PASSERI, D. L.; HAGEN, S. C.; MEDEIROS, S. C.; BILSKIE, M. V.; ALIZAD, K.; WANG, D. The dynamic effects of sea level rise on low-gradient coastal landscapes: A review. Earth's Future, v. 3, p. 159-181, 2015. DOI:10.1002/2015EF000298

PAINEL BRASILEIRO DE MUDANÇAS CLIMÁTICAS (PBMC). Impacto, vulnerabilidade e adaptação das cidades costeiras brasileiras às mudanças climáticas: Relatório Especial do Painel Brasileiro de Mudanças Climáticas. In: MARENGO, J.A.; SCARANO, F.R. (eds.). COPPE - UFRJ. Rio de Janeiro, 2016. $184 \mathrm{p}$.

POULTER, B.; HALPIN, P. N. Raster modelling of coastal flooding from sea-level rise. International Journal of Geographical Information Science, v. 22, n. 2, p. 167-182, 2007.

RAJI, O.; DEL RÍO, L.; GRACIA, F. J.; BENAVENTE, J. The use of LIDAR data for mapping coastal flooding hazard related to storms in Cádiz Bay (SW Spain). Journal of Coastal Research, v. 64, p.1881-1885, 2011.

RODRÍGUEZ, J. F.; SACO, P. M.; SANDI, S.; SAINTILAN, N.; RICCARDI, G. Potential increase in coastal wetland vulnerability to sea-level rise suggested by considering hydrodynamic attenuation effects. Nature Communications, v. 8, p.16094, 2017.

SILVA, A. F.; TOLDO JR, E. E.; WESHENFELDER, J. Morfodinâmica da embocadura da lagoa de Tramandaí (RS, Brasil). Pesquisas em Geociências, v. 44, n. 1, p. 155-166, 2017.

SMALL, C.; NICHOLLS, R. J. A global analysis of human settlement in coastal zones. Journal of Coastal Research, v. 19, n. 3, p. 584-599, 2003.

STAMMER, D. A.; CAZENAVE, A.; PONTE, R. M.; TAMISIEA, M. E. Causes for contemporary regional sea level changes. Annual Review of Marine Science, v. 5, n. 1, p. 21-46, 2013.

STOCKDON, H. F.; HOLMAN, R. A.; HOWD, P. A.; SALLENGER JR, A. H. Empirical parameterization of setup, swash, and runup. Coastal Engineering, v. 53, n. 7, p. 573-588, 2006.

TAKAGI, H.; ESTEBAN, M.; TAKAHITO, M.; DAISUKE, F. Projection of coastal floods in 2050 Jakarta. Urban Climate, v. 17, p. 135-145, 2016.

TOLDO JR., E. E.; DILlENBURG, S.; ALMEIDA, L.; TABAJARA, L.; MARTINS, R.; CUNHA, L. Parâmetros morfodinâmicos da Praia de Imbé, RS. Pesquisas em Geosciências, v. 20, n. 1, p. 27-32, 1993.

TOLDO JR, E. E.; NICOLODI, J. L.; ALMEIDA, L.; CORRÊA, I.; ESTEVES, L. Coastal dunes and shoreface width as a function of longshore transport. Journal of Coastal Research, v. 39, p. 390-394, 2006.

VIANNA, H. L.; CALLIARI, L. J. Variabilidade do sistema praia-dunas frontais para o litoral norte do Rio Grande do Sul (Palmares do Sul a Torres, Brasil) com o auxílio do Light Detection and Ranging - Lidar. Pesquisas em Geociências, v. 42, n. 2, p. 141-158, 2015. 
VITOUSEK, S.; BARNARD, P. L.; FLETCHER, C. H.; FRAZER, N.; ERIKSON, L.; STORLAZZI, C. D. Doubling of coastal flooding frequency within decades due to sea-level rise. Scientific Reports, v. 7, 2017, p. 1399.

WADEY, M. P.; COPE, S. N.; NICHOLLS, R. J.; MCHUGH, K.; GREWCOCK, G.; MASON, T. Coastal flood analysis and visualization for a small town. Ocean \& Coastal Management, v. 116, p. 237-247, 2015. DOI:10.1016/j.ocecoaman.2015.07.028

\section{Biografia do autor principal}

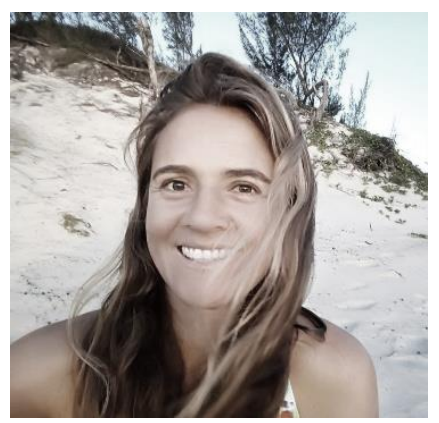

Possui graduação em Oceanografia pela Universidade do Vale do Itajaí (UNIVALI), completada em 2006, mestrado pela Universidade Federal de Santa Catarina (UFSC), finalizado em 2010 e doutorado pela Universidade Federal do Rio Grande do Sul, área de Geologia Marinha, concluído em 2019. Atuou em Projetos de Pesquisas do Centro de Estudos de Geologia Costeira e Oceânica (CECO). Foi professora substituta na Universidade Estadual de Santa Catarina (UDESC) entre os anos de 2013 e 2016 e, professora horista da Universidade do Sul de Santa Catarina (UNISUL) entre 2010 e 2019. Tem experiência nas áreas de Gerenciamento Costeiro, Geologia Marinha e Geomorfologia Costeira.

Esta obra está licenciada com uma Licença Creative Commons Atribuição 4.0 Internacional - CC BY. Esta licença permite que outros distribuam, remixem, adaptem e criem a partir do seu trabalho, mesmo para fins comerciais, desde que lhe atribuam o devido crédito pela criação original. 